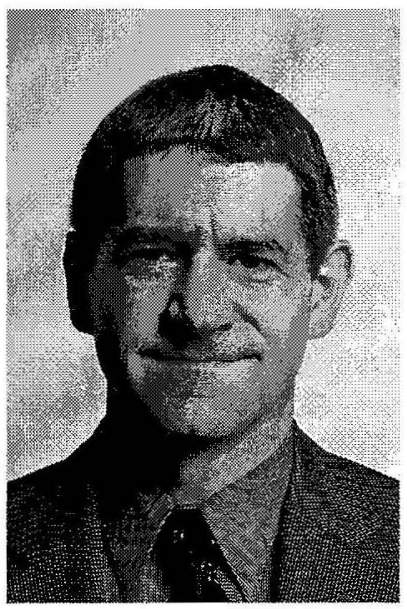

\title{
THE PROBLEM RESOLUTION FRAMEWORK UNDER THE EMPLOYMENT RELATIONS ACT 2000
}

\author{
Andrew Annakin' \\ General Manager, Employment Relations \\ Service, Department of Labour
}

\begin{abstract}
The Employment Relations Act 2000 provides options for interventions to support employment relationships and to prevent and solve employment relationship problems. These interventions follow a hierarchy of roles established by the Act, involving the availability of mediation services in all its forms (including best practice information and assistance), the investigative role of the Employment Relations Authority, and the judicial role of the Employment Court. These problem solving processes act as a continuum, with people able to move between the different, but complementary, forms of assistance. This paper discusses those processes in terms of the services that are available, developments in the first two years under the Employment Relations Act, and the challenges ahead.
\end{abstract}

\section{Introduction}

The Department of Labour's Employment Relations Service (ERS) has the responsibility to support and implement the objectives of the Employment Relations Act 2000 (ERA).

The objective of the Act is to build productive employment relationships through the promotion of mutual trust and confidence in all aspects of the employment environment and of the employment relationship by:

- recognising that employment relationships must be built on good faith behaviour;

- acknowledging and addressing the inherent inequality of bargaining power in employment relationships;

- promoting collective bargaining;

- protecting the integrity of individual choice;

- promoting mediation as the primary problem-solving mechanism; and

- $\quad$ reducing the need for judicial intervention.

To achieve these objectives the ERA provides a framework of interventions, implemented and supported by the ERS. The purpose of the ERS is to promote and support fair and productive employment relationships, and to do so we provide a variety of interventions. These include:

- $\quad$ best practice guides and fact sheets;

- the provision of information by the ERS Infoline and website;

- labour inspectors;

- mediation in all its forms;

- the investigative role of the Employment Relations Authority; and

- the judicial role of the Employment Court.

These problem-solving interventions act as a continuum, with people able to move between the different, but complementary forms of assistance, the mix being chosen to suit the features and needs of the case at hand. These are all part of the 'tool-box' that parties to employment relationships can access when required.

In delivering these services, we have a focus on shortterm to long-term outcomes:

- in the short-term, we aim to align our services as accessible, integrated and to create awareness of the services we offer;

- in the medium-term our goal is to be a best practice clearing house where our primary function is the dissemination of best practice information so as to prevent problems from arising, and if they do, to give people the tools to solve those problems themselves;

\footnotetext{
${ }^{1}$ The views expressed in this paper are those of the author, and are not necessarily the views of the Department of Labour.
} 
- our overall long-term mission is: 'excellent working relationships, a fact of working life'.

This paper discusses the continuum of problem resolution interventions as they have operated during the first two years under the ERA, and the challenges ahead for effective service delivery to achieve our long-term mission.

\section{Proactive intervention, information provision \& assistance}

The first step of the continuum is the proactive area of information provision and promoting best practice. These interventions fit with the wider concept of 'mediation services' that the ERS offers. Our proactive work aims to provide employees and employers with the tools, through best practice guidance, to prevent problems from arising in the first instance, or if they do arise, by giving parties the tools to solve their problems themselves.

To this end, Auckland-based Employment Relations Infoline staff (who primarily answer enquiries about employment relations matters) conducted 252 talks or seminars attended by approximately 8,000 people with groups and organisations throughout the Auckland region during the first two years of the ERA.

In addition to talks given by Infoline information officers, labour inspectors participated in 327 talks or seminars attended by approximately 3,000 people, and mediators participated in 668 seminars, talks or visits attended by approximately 12,000 people. Recent talks have been directed to general businesses, community groups, Maori community groups, employment lawyers and practitioners, and university industrial relations students.

The ERS has published various best practice booklets and factsheets on employment rights. Best practice titles include:

- Collective bargaining under the Employment Relations Act - in good faith;

- Employment relationship problems - what they are, how to prevent them, how to fix them;

- Hiring new employees in the Employment Relations Act environment;

- Using mediation services effectively

People are increasingly seeking information on their own accord. The ERS website received an average of 91,853 page requests per month from 11 December 2000 (when it went on-line) to the end of September 2002. Page requests have increased with an average of 160,321 requests over the past six months, compared with an average of 66,177 from when it when on-line to the end of March 2002. A portion of the increase can be attributed to enquires about paid parental leave and usage of the paid parental leave on-line calculator. ERS publications and factsheets, however, remain the most requested items.

In total, the ERS answered 435,458 enquiries on employment related matters since the implementation of the ERA to 30 September 2002, of which 67,709 were answered during the September 2002 quarter.

The most frequent enquires type related to matters of special leave and holidays at $26 \%$ of all enquiries, followed by employment agreement issues (15\%), wages (13\%), employment relationship problems (9\%), dismissal, redundancy and resignation issues (8\%), followed by parental or paid parental leave enquiries $(6 \%)$. Of note is that, due to the implementation of the paid parental leave scheme, $16 \%$ of all enquiries related to parental or paid parental leave in the September 2002 quarter.

During the two years, Infoline staff also completed 3,150 enquiries that required an information officer to provide information to more than one party. In such situations, an offer is made by the officer to contact another party to ensure that the other party is aware of their obligations under the relevant employment legislation, this role being part of the wider scope of mediation services.

In their role of investigating breaches of the minimum code of employment, labour inspectors conducted 447 proactive inspections from 2 October 2000 to 30 September 2002. Of the 121 proactive inspections conducted over the six months to 30 September 2002, 47 breaches were discovered. Recent visits have targeted restaurants and cafes, and the agriculture and forestry industries.

The Labour Inspectorate received 4,051 complaints during the first two years under the ERA. The number of complaints has fluctuated between quarters, with 630 complaints received in the September 2002 quarter, compared with 554 in the previous quarter and 432 in the September 2001 quarter.

The vast majority of complaints (76\%) concerned breaches of the Holidays Act $-49 \%$ of complaints related to annual holidays, $21 \%$ related to public holidays, and $6 \%$ related to special leave. The remaining main types of complaints related to the minimum wage and the Wages Protection Act (both 9\%). A comparison of quarters reveals that the types of complaints do not fluctuate greatly over time. In conducting an investigation, inspectors will inform employers of minimum employment rights and how to best insure compliance with those rights.

\section{Mediation}

The next step of the continuum is mediation. 'Mediation' is to be understood as a broad concept; is not restricted to 'formal' mediated meetings. It includes the provision of the above mentioned best practice information to assist in 
facilitating the successful resolution of problems when they arise at the workplace level, and also mediations conducted by telephone, e-mail, faxes and letters.

Mediation, in all its forms, is proving to be popular. This stands in contrast to a view held by employers we have encountered in the past. ${ }^{2}$ This was that problems should be resolved internally, and those that end up in external mediation were serious, and therefore whatever the outcome, there would be a damaged relationship. This view may have reflected a perception that using external mediation involves bringing in 'outsiders' and escalating the problem. This view, however, appears to be weakening.

\section{Problem resolution in the workplace}

Research $^{3}$ also tells us that problem resolution procedures are used in the workplace to resolve problems - it is not just something people come to us for. The typical process of dispute resolution involves the employee informing his or her supervisor or union representative of the problem, followed by a meeting of the parties to the dispute. Following this, there are differences between small and large employers.

In smaller businesses the owner is often the 'senior manager' and there are unlikely to be human resources specialists with the expertise to assist in resolving problems when they first arise. For employees, this is often seen as something that leads to problems as they, particularly those without union support, feel they need additional help. This is because the person that was perceived as causing the problem is often the same person who the employee would otherwise bring the problem to.

Large and medium employers (50 or more employees) follow slightly different dispute processes to smaller employers. Larger size usually means that formal dispute procedures are in place using specialised human resources expertise.

Employers of all sizes said that a majority of problems are resolved when the employee first brings the dispute forward. If it is not, the problem is often resolved at the first meeting between all the parties, particularly if a human resources professional becomes involved as a facilitator. If a problem remains unresolved after a series of in-house meetings, the dispute would go to mediation, which is usually conducted by an ERS mediator or, on occasion, a private provider. The Authority is considered the next step if mediation could not resolve the dispute.

\section{The numbers}

Despite the fact that problem resolution processes are used in the workplace, most of our resources go into

2 UMR Research Ltd, "Disputes and disputes resolution procedures", January 2002.

${ }^{3}$ Ibid. facilitating fast and effective problem solving. In the first two years of the ERA, the ERS received or reopened 15,336 requests for mediation assistance. In recent quarters there has been an increase in the number of mediation requests with 2,524 applications opened or reopened in the September 2002 quarter and 2,472 in the previous quarter. This compares with 1,970 in the March 2002 quarter and 2,078 in the September quarter one year ago.

During the first two years under the ERA, personal grievances comprised $62 \%$ of all completed mediation applications. Of personal grievances, unjustifiable dismissal were $61 \%$ and disadvantage grievances were $21 \%$. The table below illustrates a breakdown of the main types of mediation applications completed.

\begin{tabular}{|l|c|}
\hline Bargaining & $4.7 \%$ \\
\hline Good Faith & $2.5 \%$ \\
\hline Disciplinary Problems & $2.2 \%$ \\
\hline Dispute & $2.2 \%$ \\
\hline Individual Agreement & $4.3 \%$ \\
\hline Minimum Code & $1.6 \%$ \\
\hline Other & $8.6 \%$ \\
\hline Personal Grievance & $61.7 \%$ \\
\hline Recovery of Wages & $6.4 \%$ \\
\hline Redundancy & $5.8 \%$ \\
\hline
\end{tabular}

Mediators completed 14,357 applications during the period, with only $12.8 \%$ recorded as 'not settled'. The table below illustrates a breakdown of the manner in which all applications were disposed of.

\begin{tabular}{|l|c|}
\hline Mediated Settlements & $51.9 \%$ \\
\hline Not Settled & $12.8 \%$ \\
\hline Withdrawn & $3.7 \%$ \\
\hline Not Proceeding & $14.1 \%$ \\
\hline Mediator Decision & $0.4 \%$ \\
\hline Recorded Settlement & $15.0 \%$ \\
\hline Partial Settlement & $0.9 \%$ \\
\hline Other & $1.1 \%$ \\
\hline
\end{tabular}

Terms of settlement varied widely in the 9,797 cases that were either mediated settlements, partial settlements, recorded settlements or mediator decisions. For example, reinstatement was the outcome (or part of the outcome) in 238 cases and 3,921 ( $40 \%$ of) cases incorporated a nonmonetary outcome (eg., a letter of apology, a reference to be given, property returned, or promises of different behaviour etc).

Speed is also an important factor in resolving problems. In the first two years of the ERA, $75 \%$ of applications were completed in six weeks.

A variety of methods are used to assist in resolving employment relationship problems, not just formal mediated meetings. Of actions recorded by the ERS in attempts to resolve problems over the past two years, phone calls comprised $56 \%$ of all events, $30 \%$ of events were mediated meetings, $6 \%$ were letters, $4 \%$ were faxes, and $4 \%$ were e-mails. 
All this results in clients largely being satisfied with their mediation. In the quarter ended 30 September 2002, 86\% of surveyed users of ERS mediation services were either 'very satisfied' or 'satisfied' with the overall handling of their issue.

\section{Employment relationship problems $v$ s personal grievances}

An important distinction disguised by the numbers is that between an employment relationship problem and a personal grievance. Increasingly problem resolution activity deals with employment relationship problems not founded on a legal dispute under the ERA (such as a personal grievance). These have included feuding employees where an employer or union representative have wanted to bring the two employees together. Another example is a performance issue that is brought to mediation before there is either formal disciplinary action or before a formal grievance has been submitted. In short, they are lower-level problems, compared with a more formal and serious personal grievance.

Mediation, in all its forms, is increasingly becoming the first port of call for such employment relationship problems, particularly where it is acknowledged that an initial problem might escalate into a personal grievance, permanently souring the relationship, if left unattended. Mediation, in this context, includes people accessing best practice information and guides from the ERS Infoline and website in attempts to resolve problems themselves, as well as meeting with a mediator. The result of such early intervention is often that employment relationship problems are resolved before they become formal personal grievances. Potential outcomes of an ended employment relationship or a monetary settlement are accordingly averted.

The resolution of such problems is quite different from the resolution of a 'standard' personal grievance, as it is often inappropriate to have a written settlement agreement. Sometimes, all that is required is a structured discussion between the parties in front of a mediator where the parties themselves record the key points of agreement, either verbally or in writing. This is also the case where parties are dealing with interpersonal relationship difficulties: settlement may take the form of agreed protocols rather than a 'full and final'-type settlement, given the ongoing nature of the relationship.

\section{The challenge ahead}

The concept of mediation services is now increasingly seen more of a tool for resolving employment relationship problems and maintaining relationships rather than a road of last resort. Therefore, we run the risk of being oversubscribed. This is particularly the case with respect to smaller businesses, which often do not have the human resources expertise to provide assistance internally, and may be more eager to use ERS-provided mediation. This oversubscription can become even more pronounced when there are many ongoing collective bargaining mediations, which require a higher concentration of resources than those put into other types of mediations.

With a system that needs to be fast to be effective, we can be the victims of our own success. We need to reduce our reactive caseload, not only for the sake of maintaining our efficiency and effectiveness, but more importantly so we can achieve our mission of making excellent working relationships a fact of working life. The manner that both are achieved is through proactive intervention by informing people of best practice to prevent basic employment relationship problems from arising. If problems do arise, our job is to give people the tools to support the problem resolution procedures that are already used in the workplace, allowing those problems to be resolved in the first instance. In doing so, problems are less likely to sour into formal personal grievances that need 'formal' mediation, and the employment relationship can be maintained.

Resources put into the proactive area, however, take away from our responsiveness in the reactive area. The challenge is to find a balance between the two to best achieve our mission.

\section{Employment Relations Authority}

\section{Interaction with the continuum}

The Act recognises that there will always be some cases that mediation will not be able to resolve, and will require judicial intervention. The next step on the problem resolution continuum is the Employment Relations Authority - a specialist decision-making body that is not inhibited by strict procedural requirements.

In understanding the work of the Authority, it is important to understand its interaction with mediation. Before investigating any matters, Authority members must first consider whether mediation can assist the parties. Authority support officers and mediation support officers will often liaise to discuss whether mediation can be effective. Workflows exist along the continuum with parties passing from mediation to the Authority, when mediation has not solved the problem, and vice versa when it is thought mediation can best assist.

In accordance with its obligations under the Act to first consider whether mediation can assist the parties in resolving their problems, over the first two years of the ERA, the Authority referred or directed 1,818 applications to mediation. This represents approximately $50 \%$ of all Authority applications, although for a small number of applications, a decision will not have yet been 
made as to whether the application is to be referred to mediation. ${ }^{4}$

The ERS analyses the outcomes of applications that have been referred or directed to mediation from the Authority. From 1 October 2001 to 30 September 2002 (the first full year the measure has been active), 863 applications that were referred or directed to mediation from the Authority were recorded as completed. Of the manner in which applications were primarily disposed, $57 \%$ were mediated settlements, $26 \%$ were not settled, $10 \%$ were not proceeding, $2 \%$ were recorded settlements, and $2 \%$ were withdrawn.

\section{The investigative process}

The Authority aims to be low-level and speedy, and as mentioned, must first consider whether mediation can assist the parties reach a resolution. The Authority is an investigative body charged with resolving problems by establishing the facts and making determinations according to the substantial merits of the case, without regard to technicalities. The Authority aims to make its processes fast and effective. There is, however, a balance that needs to be maintain between what people expect from the process and natural justice, and the need to be speedy; it is important not to compromise the former for the sake of the latter.

The Authority has been fast and effective, with $75 \%$ of applications completed within five months. In total, the Authority received 3,634 applications over the first two years of the ERA, and completed 2,716 applications. The table below provides a breakdown of the primary manner in which all completed applications were disposed of.

\begin{tabular}{|l|c|}
\hline Determined & $29.0 \%$ \\
\hline Investigation Abandoned & $14.5 \%$ \\
\hline Remove to Court & $0.4 \%$ \\
\hline Withdrawn & $53.1 \%$ \\
\hline Other & $2.8 \%$ \\
\hline
\end{tabular}

In attempting to establish the facts and determine what is at the root of a problem, an encyclopedia of evidence is unnecessary. Instead it is important to afford the parties an opportunity to agree on key facts, which allows for the parties to potentially reach agreement in other areas. When there is agreement on key facts, it is also unnecessary to have witnesses examined and crossexamined on every point. To this end, a conference call is an important vehicle for solving a problem, as it is used to hear preliminary matters and decide points of agreement.

Following a conference call, an investigative meeting determines the real nature of the problem, which often might be different from what the parties believe. Prior to an investigative meeting, Authority members will ask

\footnotetext{
${ }^{4}$ The figure of $50 \%$ includes those applications to the Authority that applied directly to mediation, and where mediation was unable to solve the problem.
}

which witnesses should be heard from in order to determine the nature of the problem. These witnesses may be different from whom the parties or their representatives might select as witnesses, if it were solely their decision.

In the course of an investigation, Authority members will ask questions as impartial third parties, creating an environment that is relaxed, as opposed to a more confrontational setting of an apposing representative cross-examining a witness, where the perception of the witness might be that the representative is 'out to get them'. In short, it is about the Authority member bringing together the most appropriate information and witnesses that can best assist in determining the problem.

\section{Challenges to determinations}

The numbers indicate that parties feel a sense of closure and are satisfied that the Authority determination has sufficiently dealt with the problem, while adhering to principles of natural justice. This is evidenced through the small number of judgments for de novo challenges to Authority determinations issued by the Employment Court - the Court being the final step of the continuum.

As mentioned, the Authority completed 2,716 applications over the first two years of the ERA; 788 were determinations. The Employment Court received 223 applications under the ERA to the end of September 2002, which resulted in 229 application types - 141 were for de novo challenges of an Authority determination. The complete numbers and percentages of applications received by type by the Employment Court were:

\begin{tabular}{|l|c|}
\hline Challenge - seeking de novo & $141(61.6 \%)$ \\
\hline Challenge - point of law or fact & $30(13.1 \%)$ \\
\hline Declaration - strike, lockout or picket & $3(1.3 \%)$ \\
\hline Declaration whether employee & $6(2.6 \%)$ \\
\hline Entry warrant to dwellinghouse & $1(0.4 \%)$ \\
\hline Interim dec. - strike, lockout, picket & $1(0.4 \%)$ \\
\hline Interim inj. - strikes, lockouts, picket & $6(2.6 \%)$ \\
\hline Injunction - strikes, lockouts, picket & $10(4.4 \%)$ \\
\hline Proceedings removed in full from ERA & $19(8.3 \%)$ \\
\hline Proceedings removed in part from ERA & $1(0.4 \%)$ \\
\hline Review & $5(2.2 \%)$ \\
\hline Referral of question of law from ERA & $2(0.9 \%)$ \\
\hline Special leave to remove authority proceedings & $3(1.3 \%)$ \\
\hline
\end{tabular}

One hundred and thirty-seven applications made under the ERA were completed by the Employment Court - 61 were judgments, 72 were withdrawn and 4 were administrative withdrawals. Of the 61 judgments issued, only 27 were issued for a challenge de novo of an Authority determination. This is to say that only three percent of determinations issued by the Authority have had a judgment issued by the Employment Court for a de novo challenge.

The relative lack of challenges to the Employment Court, to a degree, indicates that people are satisfied with their Authority experiences and shows an acceptance of the 
informal environment of the Authority. While recognising and accepting that there will always be cases involving important questions of law that require judicial intervention, people do not necessarily always want the legal technicalities of a lengthy court judgment. In accordance with the role of the Authority being an investigative body that resolves problems according to the substantial merits of the case, without regard to technicalities, determinations are written to assist the parties rather than being a document that provides a foundation for an appeal to court.

\section{Conclusion}

The ERS has been charged with delivering a service based on the principles of the ERA, and in doing so, we have come across challenges and issues we want to address. It has involved a steep learning curve. We have largely been successful in delivering on the principles of the Act. However, the successes we have had also increase the degree to which people use the services we offer. The success of the system depends largely on the degree to which we can offer fast and effective services.

It is the first step of the continuum - the provision of information and best proactive guidance - that we will continue to focus on. It is the proactive and educative work that will both avoid problems from initially arising, and also allow problems to be resolved in the workplace, leading to excellent working relationships being a fact of working life. 